CZASOPISMO INŻYNIERII LĄDOWEJ, ŚRODOWISKA I ARCHITEKTURY JOURNAL OF CIVIL ENGINEERING, ENVIRONMENT AND ARCHITECTURE

JCEEA, t. XXXIV, z. 64 (2/II/17), kwiecień-czerwiec 2017, s. 247-254, DOI:10.7862/rb.2017.96

Halina GARBALIŃSKA ${ }^{1}$

Magdalena BOCHENEK ${ }^{2}$

\title{
OCENA MOŻLIWOŚCI WYZNACZANIA IZOTERM SORPCJI DYNAMICZNĄ METODĄ DVS - NA PRZYKŁADZIE BETONU KOMÓRKOWEGO KLASY 700
}

\begin{abstract}
Artykuł prezentuje ocenę porównawczą dynamicznej metody wyznaczania izoterm sorpcji (DVS) oraz tradycyjnej metody pomiarowej (TM). Problem omówiono na przykładzie betonu o gęstości $700 \mathrm{~kg} / \mathrm{m}^{3}$, przedstawiając uzyskane dla tego materiału wyniki badań. Wyznaczono izotermy sorpcji metodą tradycyjną z zastosowaniem nasyconych wodnych roztworów soli oraz metodą zautomatyzowaną z wykorzystaniem urządzenia generującego wilgotność. Porównując czas trwania i nakład pracy przy realizacji obydwu eksperymentów stwierdza się występowanie znaczących różnic. Wyznaczenie izoterm sorpcji metodą tradycyjną trwało 10 miesięcy i było poprzedzone intensywną pracą związaną z przygotowaniem eksperymentu. Natomiast pomiar urządzeniem DVS dla 1 próbki trwał około 1 doby i nie wymagał specjalnego przygotowania próbek oraz wykonywania roztworów. Czas tego typu pomiarów został skrócony z wielu miesięcy do kilkudziesięciu godzin. Wyniki zebrane obydwiema metodami odznaczają się bardzo dobrą zgodnością w zakresie wilgotności względnych powietrza od $0 \%$ do $75 \div 85 \%$. Natomiast w zakresie wysokich wilgotności od $75 \div 85 \%$ do $98 \%$ zdiagnozowano występowanie znaczących różnic $\mathrm{w}$ przebiegach izoterm sorpcji wyznaczonych przy pomocy obydwu metod. Zrealizowane dwa bloki eksperymentalne pozwalają stwierdzić, że w przypadku testowanego betonu komórkowego, szybka metoda pomiarowa DVS może być stosowana do diagnostyki wilgotnościowej oraz wyznaczania izoterm sorpcji w szerokim zakresie wilgotności, $\mathrm{z}$ wyłączeniem jednak zakresu ponadkrytycznego.
\end{abstract}

Słowa kluczowe: izotermy sorpcji, beton komórkowy, tradycyjna metoda wyznaczania izoterm, dynamiczna metoda wyznaczania izoterm, DVS

${ }^{1}$ Autor do korespondencji / corresponding author: Halina Garbalińska, Zachodniopomorski Uniwersytet Technologiczny w Szczecinie, Wydział Budownictwa i Architektury, Al. Piastów 50, 70-311 Szczecin, tel. 9144948 29, e-mail: Halina.Garbalińska@ zut.edu.pl

2 Magdalena Bochenek, Zachodniopomorski Uniwersytet Technologiczny w Szczecinie, Wydział Budownictwa i Architektury, Al. Piastów 50, 70-311 Szczecin, tel. 9144945 14, e-mail: Magdalena.Bochenek@zut.edu.pl 


\section{Wstęp}

Izotermy sorpcji opisują związek między stabilizującą się w danym materiale zawartością wilgoci i wilgotnością panującą w jego otoczeniu. Izotermy sorpcji umożliwiają określenie: zdolności materiału do chłonięcia wody, krytycznej zawartości wilgoci, charakterystyki mikrostruktury, a przede wszystkim równowagowej wilgotności materiału, odpowiadającej danej temperaturze i wilgotności względnej powietrza.

Metody wyznaczania izoterm sorpcji można generalnie podzielić na statyczne i dynamiczne. Tradycyjną metodą badania sorpcji materiałów budowalnych jest grawimetryczna metoda statyczna, opisana m.in. w normie europejskiej [4] oraz normie amerykańskiej [1]. Obydwie normy podają dwie alternatywne metody określania właściwości sorpcyjnych porowatych materiałów budowlanych: z zastosowaniem eksykatorów oraz z zastosowaniem komory klimatycznej. Zalecana temperatura badań to $23^{\circ} \mathrm{C}-$ dla warunków standardowych oraz $27^{\circ} \mathrm{C}$ - dla warunków tropikalnych.

Metodą alternatywną do metody tradycyjnej jest metoda zautomatyzowana wykorzystująca urządzenia generujące wilgotność, jak np. Dynamic Vapor Sorption (DVS). Instrumenty te bazują na strategii nazywanej $\mathrm{d} m / \mathrm{d} t$ (procentowa zmiana masy w funkcji czasu) pozwalającej ustalić, czy poziom równowagi został osiągnięty. Wartość $\mathrm{d} m / \mathrm{d} t$ jest obliczana w oparciu o pomiar masy $\mathrm{z}$ ostatnich minut eksperymentu. Gdy $\mathrm{d} m / \mathrm{d} t$ jest bliskie zero oznacza to, że próbka zbliża się do osiągnięcia stanu równowagi.

Wiarygodność pomiarów tym urządzeniem potwierdzają badania prowadzone $w$ innych gałęziach przemysłu, m.in. farmaceutycznym, spożywczym, tekstylnym. Stwierdza się jednak brak usystematyzowanych badań porównawczych metody tradycyjnej z metodą zautomatyzowaną w odniesieniu do materiałów budowlanych. W toku studiów literatury znaleziono jedynie nieliczne dane odnoszące się do badań porowatych materiałów budowlanych.

\section{Opis procedury badawczej}

\subsection{Metoda tradycyjna}

Badania izoterm sorpcji metodą tradycyjną przeprowadzono na prostopadłościennych próbkach betonu komórkowego klasy $700 \mathrm{~kg} / \mathrm{m}^{3}$ o wymiarach powierzchni czołowych $6 \times 12 \mathrm{~cm}$ i grubości ok. $1 \mathrm{~cm}$. W pierwszej kolejności zinwentaryzowano próbki pod względem wymiarów geometrycznych, a następnie wysuszono je w suszarce do stałej masy w temperaturze $105^{\circ} \mathrm{C}$. Po wysuszeniu próbki zważono na wadze o dokładności $\pm 0,001$ grama, a następnie zaizolowano na pobocznicach i ponownie dosuszono do stałej masy w suszarce w $105^{\circ} \mathrm{C}$.

$\mathrm{W}$ międzyczasie przygotowano roztwory higrostatyczne, przewidziane do późniejszego stabilizowania wilgotności względnych powietrza $\varphi$. Na podstawie 
literatury (np. [2]) wybrano następujące sole: $\mathrm{LiCl}, \mathrm{MgCl}_{2}, \mathrm{Mg}\left(\mathrm{NO}_{3}\right)_{2}, \mathrm{NaNO}_{2}$, $\mathrm{NaCl}, \mathrm{KCl}, \mathrm{K}_{2} \mathrm{SO}_{4}$, których wodne roztwory nasycone stabilizują wilgotność względną na poziomie: $11,33,54,65,75,85,98 \%$, w temperaturze $20^{\circ} \mathrm{C}$.

Poszczególne roztwory umieszczono na dnie specjalnie przygotowanych szczelnych pojemników, pełniących rolę eksykatorów. Następnie umieszczono w pojemnikach stelaże, a w nich po 4 próbki. Całe układy ulokowano w komorze termostatycznej, ustawionej na temperaturę $20^{\circ} \mathrm{C}$.

Pomiary sorpcji polegały na rejestracji zmian zwiększającej się masy próbek. Procesy sorpcji zainicjowane były wprowadzeniem suchych próbek w kontakt z powietrzem o różnym poziomie zawilgocenia. Odbywały się one według schematu: $0 \rightarrow 11 \%, 0 \rightarrow 33 \%, 0 \rightarrow 54 \%, 0 \rightarrow 65 \%, 0 \rightarrow 75 \%, 0 \rightarrow 85 \%, 0 \rightarrow 98 \%$. Początkowo pomiary wykonywano co 6 godzin, następnie co 12 godzin. Po spowolnieniu procesu sorpcji, próbki ważono co dwie doby, stopniowo wydłużając przerwy między pomiarami. Cały eksperyment trwał w sumie 10 miesięcy.

\subsection{Metoda DVS}

Ze względu na długi czas i duży nakład pracy, jakie wymagane są przy wyznaczaniu izoterm sorpcji tradycyjnymi metodami grawimetrycznymi, zdecydowano się przeprowadzić drugi eksperyment techniką DVS. Ideę pomiaru sorpcji za pomocą urządzania DVS zilustrowano na rysunku 1 . Schematyczny model oraz jego opis sporządzono na podstawie instrukcji obsługi aparatu przekazanego przez jego producenta.

$\mathrm{Z}$ wnętrza bloczków testowanej klasy betonu komórkowego wycinano próbki sześcienne o wymiarach $0,2 \times 0,2 \times 0,2 \mathrm{~cm}$, każda o masie ok. $10 \mathrm{mg}$. Badania wykonywano $\mathrm{w}$ temperaturze $20^{\circ} \mathrm{C}$ i zakresie wilgotności względnych

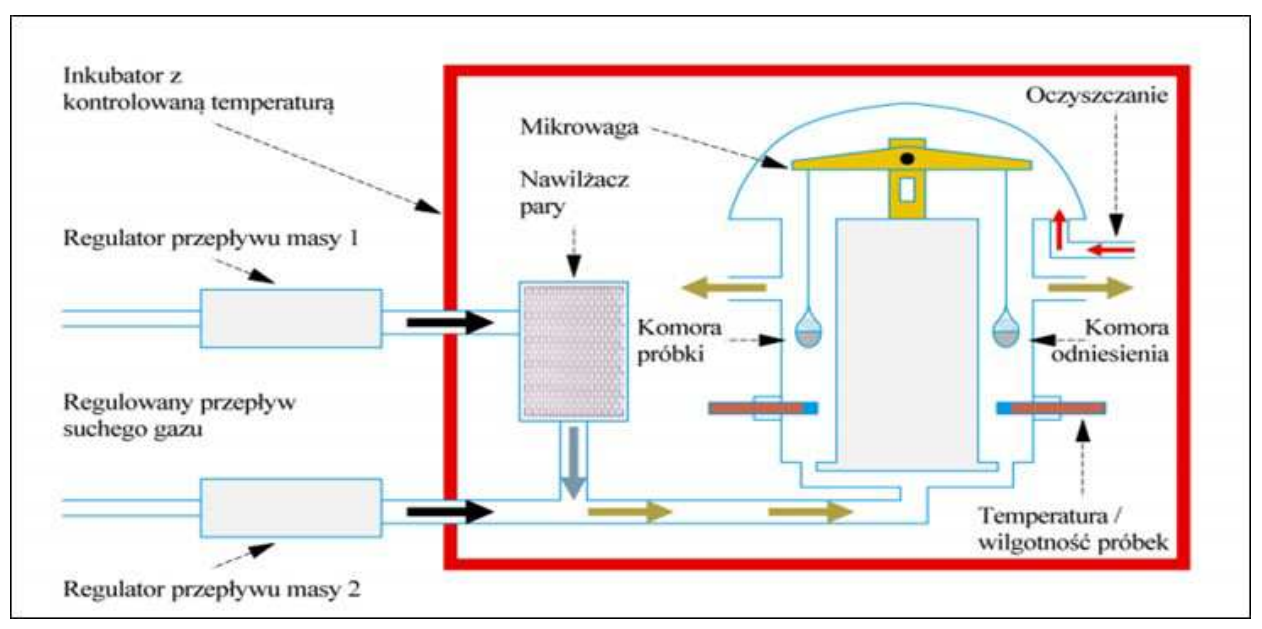

Rys. 1. Schemat pomiaru realizowanego techniką DVS, na podstawie [5]

Fig. 1. Measurement scheme of the DVS technique, based on [5] 
powietrza $0 \div 98 \%$. Ustawiono skokowe zmiany wilgotności co ok. $10 \%$ i rejestrację zmian masy co 1 minutę. Za pomocą komputera sprzężonego z urządzeniem rejestrowano zmiany masy w każdym kroku pomiarowym. Zawsze kiedy program wykrywał zmianę masy mniejszą niż $0,002 \%$ na minutę zmieniała się automatycznie wilgotność o ok. 10\%. Pomiar sorpcji jednej próbki, pozwalający odtworzyć przebieg całej izotermy, trwał około 1 doby.

\section{Wyniki badań}

\subsection{Izotermy sorpcji wyznaczone metodą tradycyjną}

Po osiągnięciu stanu równowagowego w każdym z badanych zakresów wilgotności określano masową zawartość wilgoci w materiale $U_{m}$ [\%] ze wzoru:

$$
U_{m}=\left(\frac{m_{w}-m_{s}}{m}\right) \cdot 100 \%
$$

gdzie: $m_{w}$ oznacza masę zaizolowanej próbki w stanie równowagi wilgotnościowej, $m_{s}$ to masa zaizolowanej próbki wysuszonej do stałej masy, zaś $m$ oznacza masę suchej próbki bez izolacji. Dokonano tu rozróżnienia między $m_{s}$ a $m$, aby odnieść realną zawartość wody $\left(m_{w}-m_{s}\right)$ do masy rdzennego materiału $m$, tj. betonu komórkowego pozbawionego izolacji na pobocznicy.

$\mathrm{W}$ tabeli 1 przedstawiono wyniki pochodzące z pomiarów sorpcji metodą tradycyjną, uzyskane na trzech próbkach betonu komórkowego klasy 700.

Na podstawie uzyskanych wyników sporządzono izotermy sorpcji, które zestawiono na rys. 2 . Widać, że zależność $U_{m}=\mathrm{f}(\varphi)$ cechuje się stosunkowo nieznacznym przyrostem wartości przy $\varphi<85 \%$ i gwałtownym wzrostem przy $\varphi>85 \%$, dającym niemal 9-krotny przyrost wilgotności równowagowej $U_{m}$.

Tabela 1. Wyniki badań sorpcji betonu komórkowego klasy 700, uzyskane metodą tradycyjną

Table 1. Sorption test results of autoclaved aerated concrete class 700 , obtained using the traditional method

\begin{tabular}{|c|c|c|c|}
\hline $\begin{array}{c}\text { Zakres } \Delta \varphi \\
{[\%]}\end{array}$ & $\begin{array}{c}\mathrm{U}_{\mathrm{m}}[\%] \\
700 / 1\end{array}$ & $\begin{array}{c}\mathrm{U}_{\mathrm{m}}[\%] \\
700 / 2\end{array}$ & $\begin{array}{c}\mathrm{U}_{\mathrm{m}}[\%] \\
700 / 3\end{array}$ \\
\hline 0 - 11 & 0,700 & 0,734 & 0,790 \\
\hline $0-33$ & 0,947 & 0,992 & 1,108 \\
\hline $0-54$ & 1,224 & 1,309 & 1,430 \\
\hline $0-65$ & 1,363 & 1,377 & 1,397 \\
\hline 0 - 75 & 1,388 & 1,442 & 1,461 \\
\hline $0-85$ & 1,937 & 1,973 & 1,973 \\
\hline $0-98$ & 16,262 & 16,888 & 17,788 \\
\hline
\end{tabular}




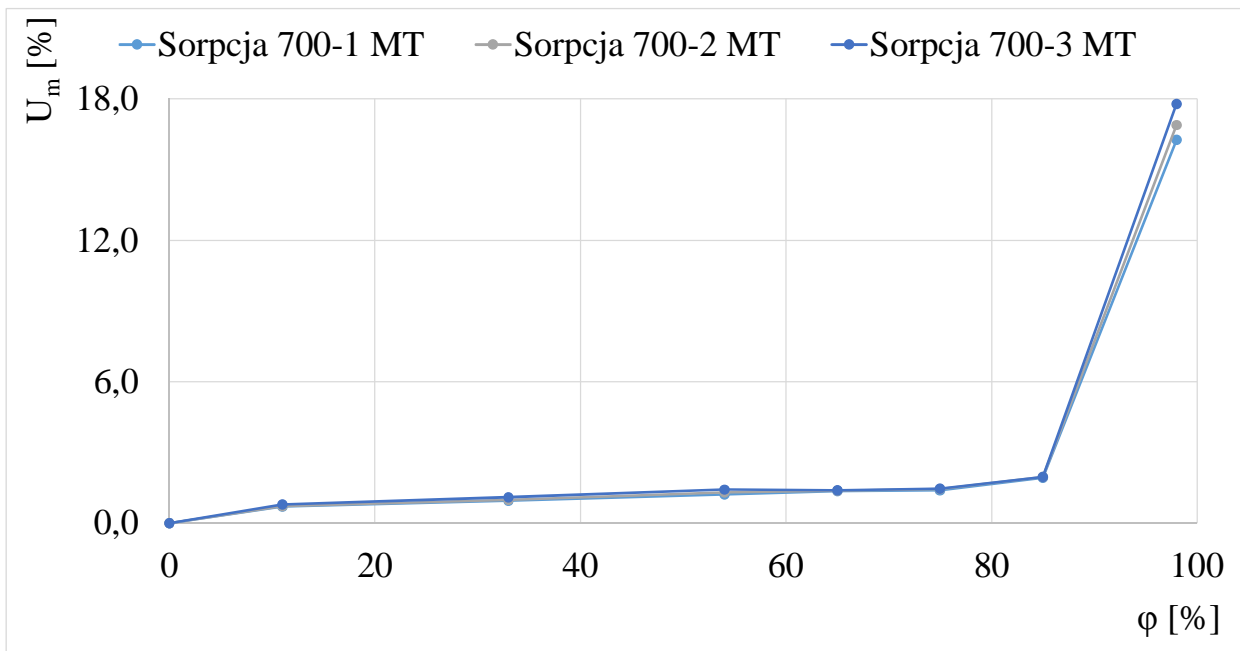

Rys. 2. Izotermy sorpcji betonu komórkowego klasy 700 wyznaczone metodą tradycyjną

Fig. 2. Sorption isotherms of AAC class 700 determined by traditional method

\subsection{Izotermy sorpcji wyznaczone techniką DVS}

W tabeli 2 przedstawiono wyniki pochodzące z pomiarów sorpcji techniką DVS, dotyczące trzech próbek analizowanego betonu komórkowego klasy 700.

Tabela 2. Wyniki badań sorpcji betonu klasy 700, uzyskane za pomocą DVS

Table 2. Sorption test results of AAC class 700, obtained using the DVS device

\begin{tabular}{|c|c|c|c|c|c|}
\hline $\boldsymbol{\varphi}[\mathbf{\%}]$ & $\begin{array}{c}\mathbf{U}_{\mathbf{m}}[\mathbf{\%}] \\
\mathbf{7 0 0 / 1}\end{array}$ & $\boldsymbol{\varphi}[\boldsymbol{\%}]$ & $\begin{array}{c}\mathbf{U}_{\mathbf{m}}[\mathbf{\%}] \\
\mathbf{7 0 0 / 2}\end{array}$ & $\begin{array}{c}\boldsymbol{\varphi} \\
{[\%]}\end{array}$ & $\begin{array}{c}\mathbf{U}_{\mathbf{m}}[\boldsymbol{\%}] \\
\mathbf{7 0 0 / 3}\end{array}$ \\
\hline $\mathbf{0 , 3}$ & 0,001 & 0,3 & 0,001 & 0,5 & 0,001 \\
\hline $\mathbf{9 , 3}$ & 0,498 & 9,9 & 0,679 & 10,2 & 0,498 \\
\hline $\mathbf{2 0 , 5}$ & 0,608 & 21,4 & 0,807 & 21,5 & 0,615 \\
\hline $\mathbf{3 0 , 6}$ & 0,670 & 31,6 & 0,891 & 31,6 & 0,687 \\
\hline $\mathbf{4 0 , 4}$ & 0,712 & 41,8 & 0,944 & 41,8 & 0,745 \\
\hline $\mathbf{5 0 , 4}$ & 0,758 & 51,9 & 0,995 & 51,7 & 0,795 \\
\hline $\mathbf{6 0 , 7}$ & 0,801 & 62,4 & 1,064 & 61,9 & 0,848 \\
\hline $\mathbf{7 1 , 1}$ & 0,855 & 72,9 & 1,178 & 72,3 & 0,913 \\
\hline $\mathbf{8 1 , 0}$ & 0,944 & 82,5 & 1,418 & 82,1 & 1,021 \\
\hline $\mathbf{9 0 , 5}$ & 1,157 & 92,0 & 2,153 & 91,5 & 1,347 \\
\hline $\mathbf{9 5 , 4}$ & 1,513 & 97,9 & 4,214 & 96,4 & 2,020 \\
\hline
\end{tabular}

Na podstawie uzyskanych wyników sporządzono izotermy sorpcji, które zestawiono na rys. 3. Odtworzone funkcje $U_{m}=\mathrm{f}(\varphi)$ cechują się umiarkowanym wzrostem wartości w przedziale $\varphi \approx 0-80 \%$ oraz nieco intensywniejszym wzrostem (od 1,6 do 3,0 razy) w zakresie najwyższych wilgotności. 


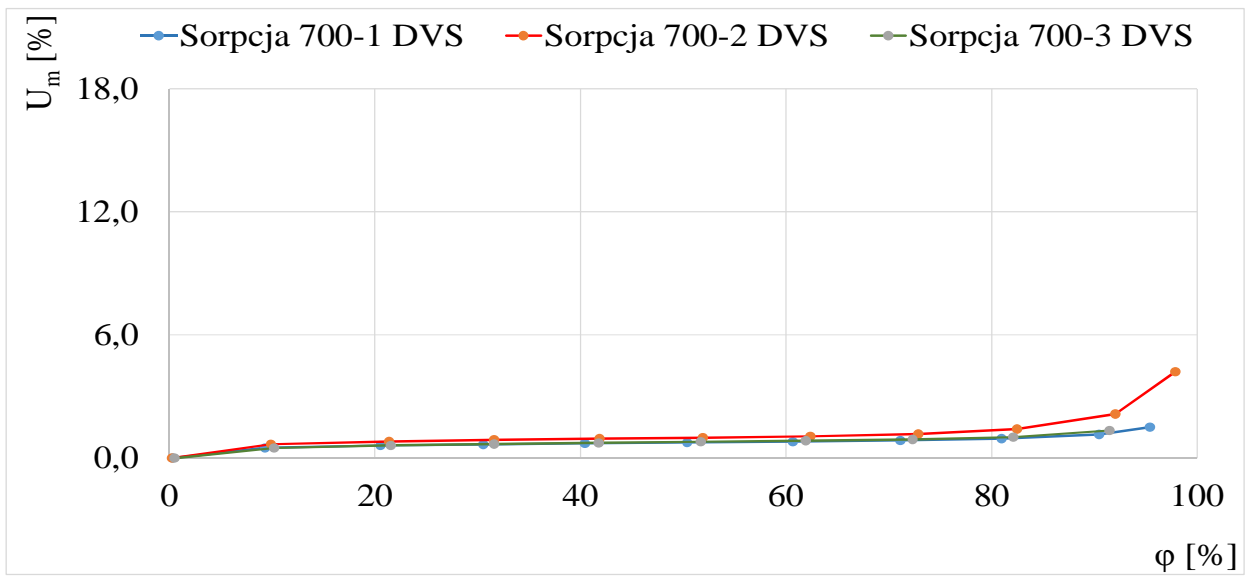

Rys. 3. Izotermy sorpcji betonu komórkowego klasy 700, wyznaczone metodą DVS

Fig. 3. Sorption isotherms of AAC class 700, determined by DVS method

\section{Podsumowanie}

Na rysunku 4 zestawiono wykresy izoterm sorpcji betonu komórkowego klasy 700, wyznaczone dwiema różnymi metodami.

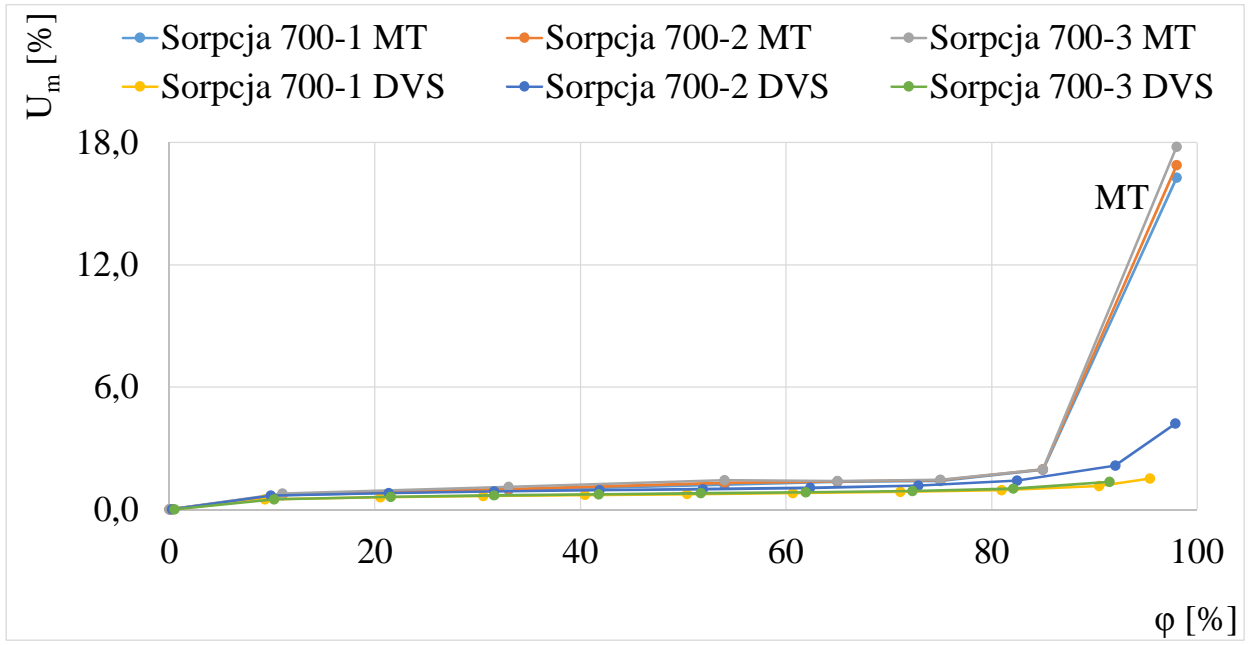

Rys. 4. Izotermy sorpcji betonu komórkowego klasy 700 wyznaczone metodami DVS oraz MT Fig. 4. Sorption isotherms of autoclaved aerated concrete class 700 determined by DVS and MT methods

Na rysunku 4 oznaczono wyniki uzyskane metodą tradycyjną jako MT, zaś metodą zautomatyzowaną jako DVS. 
Można stwierdzić bardzo dobrą zgodność wyników uzyskanych dwoma testowanymi metodami w zakresie wilgotności względnych powietrza do $75 \div 85 \%$. Jednak przy wilgotnościach obejmujących zakres od $75 \div 85 \%$ do $98 \%$ różnice w wynikach badań są bardzo duże. Tendencje te wykazują pełną analogię do wcześniej publikowanych danych dotyczących betonu komórkowego klasy 400 [3].

Porównując czas trwania i nakład pracy przy realizacji obydwu eksperymentów można zauważyć znaczące różnice. Wyznaczenie izoterm sorpcji metodą tradycyjną trwało 10 miesięcy i było poprzedzone intensywną pracą związaną z przygotowaniem badań. Natomiast pomiar urządzeniem DVS dla 1 próbki trwał około 1 doby bez konieczności specjalnego przygotowania próbek oraz roztworów. Czas tego typu pomiarów zostaje zredukowany z wielu miesięcy do kilkudziesięciu godzin.

Zatem niewątpliwą zaletą metody DVS jest bardzo krótki czas pomiaru oraz wyeliminowanie dużego nakładu pracy związanego z przygotowaniem badań oraz z późniejszym wielomiesięcznym ważeniem próbek. Możliwe jest to dzięki pełnej automatyzacji urządzenia i wykorzystaniu oprogramowania komputerowego. Dzięki wysokiej czułości i dokładności tych aparatów, rozmiary próbek mogą być niewielkie i dzięki temu osiągnięcie równowagi następuje o wiele szybciej. Ponadto w wyniku badań urządzaniem DVS uzyskuje się większą ilość punktów pomiarowych, niż w tradycyjnym badaniu.

Jednak metoda DVS nie kwalifikuje się do zastosowania w przypadku badanych materiałów w odniesieniu do wysokich wilgotności $\varphi>75 \div 85 \%$, w których przekraczana jest już wilgotność krytyczna, a klasycznym procesom sorpcji towarzyszą procesy kondensacji kapilarnej.

Natomiast przeprowadzone badania wykazały, że obydwie metody wyznaczania izoterm sorpcji są kompatybilne w stosunkowo szerokim zakresie wilgot-

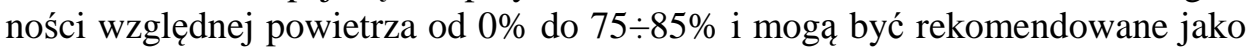
metody zamienne $w$ badaniach materiałów budowlanych testowanego rodzaju w odniesieniu do tego zakresu zawilgocenia.

\section{Literatura}

[1] ASTM C1498-04a: Standard Test Method for Hygroscopic Sorption Isotherms of Building Materials. West Conshohocken, PA, ASTM International, 2010.

[2] ASTM E104 - 02(2012) Standard practice for maintaining constant relative humidity by means of aqueous solutions. West Conshohocken, PA, ASTM International, 2012.

[3] Bochenek M., Garbalińska H.: Ocena porównawcza techniki DVS i tradycyjnej metody wyznaczania izoterm sorpcji - na przykładzie betonu komórkowego klasy 400. Fizyka Budowli w Teorii i Praktyce, Tom VII, Nr 1 - 2015, s. 15-20.

[4] PN-EN ISO 12571:2013: Cieplno-wilgotnościowe właściwości materiałów i wyrobów budowlanych. Określanie właściwości sorpcyjnych. PKN, Warszawa, 2013.

[5] Surface Measurement Systems: DVS Bedinungsanleitung. London, UK. 


\section{POSSIBILITIES EVALUATION OF DVS METHOD FOR SORPTION ISOTERM DETERMINATION - EXAMPLIFIED BY AUTOCLAVED AERATED CONCRETE CLASS 700}

\section{S u m m a r y}

This paper presents a comparative evaluation of the Dynamic Vapor Sorption method (DVS) and the traditional method (TM) to determine the sorption isotherms. The problem was discussed based on the example of autoclaved aerated concrete with a density of $700 \mathrm{~kg} / \mathrm{m}^{3}$, followed by a presentation of the results obtained for this material. Sorption isotherms were determined by use of the traditional method applied with saturated water salt solutions and the automated method applying a humidity-generating device. Comparing the extent and the amount of work throughout the conducted research and the realization of both experiments, the significant differences between both methods became apparent. The process of determination of the sorption isotherms using the traditional method required 10 months and was preceded by an intensive preparation work. On the other hand, the measurement of each sample using the DVS required about 1 day without the need to specifically prepare the samples and solutions. The length of these measurements is reduced from several months to several hours. The results obtained using both methods indicate good compatibility in the case of all the tested concretes within the air humidity range from $0 \%$ to $75 \div 85 \%$. In the case of high humidity ranges between $75 \div 85 \%$ and $98 \%$, a significant course differentiation of the sorption isotherms was determined for both methods. The two conducted experimental blocks indicate that for the tested materials the quick DVS measurement method can be used to carry out moisture diagnostics and to determine sorption isotherms for a wide range of humidity, except, however, the supercritical range.

Keywords: sorption isotherms, autoclaved aerated concrete, traditional method, Dynamic Vapor Sorption method, DVS

Przestano do redakcji: 27.05.2017 r.

Przyjęto do druku: 30.06 .2017 r. 